Int. J. Dev. Biol. 62: 827-836 (2018)

https://doi.org/10.1387/ijdb.180278fb

\title{
Prep1 (pKnox1) transcription factor contributes to pubertal mammary gland branching morphogenesis
}

\author{
LARA SICOURI ${ }^{1}$, FEDERICA PISATI ${ }^{1}$, SALVATORE PECE ${ }^{2,3}$, FRANCESCO BLASI ${ }^{*, 1}$ and ELENA LONGOBARDI*,1,4 \\ ${ }^{1}$ IFOM (FIRC Institute of Molecular Oncology), Milan, ${ }^{2}$ Department of Experimental Oncology, European Institute of \\ Oncology, Milan, ${ }^{3}$ Department of Oncology and Hemato-Oncology, University of Milan, Milan, and \\ ${ }^{4}$ Section of Pharmacology, Department of Neuroscience, University of Naples Federico II, Naples, Italy
}

\begin{abstract}
Prep1 (pKnox1) is a homeodomain transcription factor essential for in utero and postnatal development and an oncosuppressor gene in human and adult mice. We have analyzed its role in the development of the mouse mammary gland. We used Prep $1^{i / i}$ hypomorphic and Prep $1^{\mathrm{F} / F_{-}}$ Ker5CRE crosses to analyze the role of Prep1 in vivo in adult mouse mammary gland development. We also cultured mammary gland stem/progenitor cells in mammospheres to perform biochemical studies. Prep1 was expressed in mammary gland progenitors and fully differentiated mammary gland cells. Using different Prep1-deficient mouse models we show that in vivo Prep1 contributes to mammary gland branching since the branching efficiency of the mammary gland in Prep 1-deleted or Prep1 hypomorphic mice was largely reduced. In-vitro, Prep1 sustained functions of the mammary stem/progenitor compartment. Prep1-deficient mammary stem/progenitor cells showed reduced ability to form mammospheres; they were not able to branch in a 3D assay, and exhibited reduced expression of Snail1, Snail2 and vimentin. The branching phenotype associated with increased Tp53-dependent apoptosis and inability to properly activate signals involved in branching morphogenesis. Finally, Prep1 formed complexes with Snail2, a transcription factor essential in branching morphogenesis, and its absence destabilizes and promotes Snail2 proteasome-mediated degradation. We conclude that Prep1 is required for normal adult mammary gland development, in particular at its branching morphogenesis step. By binding Snail2, Prep1 protects it from the proteasomal degradation.
\end{abstract}

KEY WORDS: prep1, mammary gland, mammosphere, branching morphogenesis, transcription factor, apoptosis

\section{Introduction}

Prep1 (pKnox1) homeodomain transcription factor belongs to the TALE (Three Amino acids Loop Extension) superclass of proteins that also include Meis and Pbx (Longobardi et al., 2014). Prep1 and Pbx1 are essential during embryonic development and are required for organogenesis and differentiation (Selleri et al., 2001; Ferretti et al., 2006; Fernandez-Diaz et al., 2010). Prep1 is ubiquitously expressed both in developing and adult mice and regulates transcription by binding mostly promoters, preferentially together with Pbx1 (Penkov et al., 2013). Importantly, Prep1-Pbx dimerization regulates their subcellular localization, $\mathrm{Pbx}$ stability and DNA selectivity (Berthelsen et al., 1999; Longobardi and Blasi,
2003; Penkov et al., 2013).

In zebrafish embryos, down-regulation of Prep 1.1 causes diffuse apoptosis, hindbrain and craniofacial deficiencies and embryonic

\footnotetext{
Abbreviations used in this paper: $\mathrm{CHX}$, cycloheximide; CRE, cyclization recombinase; CT, carboxyterminal; EMT, epithelial to mesenchymal transition; HD, homeodomain; HE, hematoxylin-eosin; IF, immunofluorescence; IHC, immunohistochemistry; MaSC, mammary stem cell; MEC, mammary epithelial cell; Pbx, Pre-B cell leukemia transcription factor; p-EMT partial EMT; Prepl (pKnoxl). Pbxregulating protein 1; RT-PCR, reverse transcription-polymerase chain reaction; SFE, mammosphere forming efficiency; shRNA, short hairpin RNA; SMA, smooth muscle actin; TALE, three amino acids loop extension; TEB, terminal end bud.
}

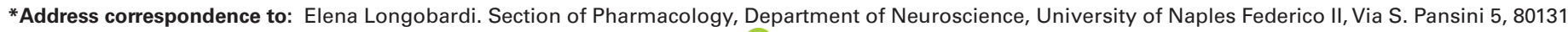
Naples, Italy.Tel: 081-7463316. Fax: 081-7463323. E-mail: elelong@libero.it - iD https://orcid.org/0000-0001-8283-4735

or Francesco Blasi. IFOM (FIRC Institute of Molecular Oncology), Via Adamello 16, 20139 Milan, Italy. Tel: 0039-02-574303288. Fax: 0039-02-574303222.

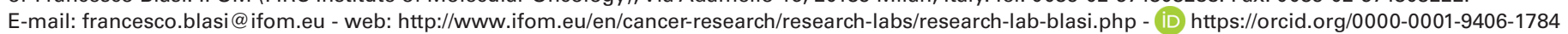

Supplementary Material (6 figures and 2 tables) for this paper is available at: https://doi.org/10.1387/ijdb.180278fb

Submitted: 27 August, 2018. Accepted: 13 September, 2018.

ISSN: Online 1696-3547, Print 0214-6282

(c) 2018 UPV/EHU Press

Printed in Spain 
lethality (De Florian et al., 2004); in mouse, Prep1-null embryos undergo Tp53-dependent apoptosis of epiblast cells and developmental arrest before gastrulation (Fernandez-Diaz et al., 2010). Mouse embryos carrying an hypomorphic Prep $1^{1 / i}$ mutation caused by the insertion of a splice site within the first intron of the gene and expressing only $2 \%$ mRNA and $3-7 \%$ protein with respect to WT, show $75 \%$ embryonic lethality at E17.5 due to major alterations in hematopoiesis; moreover, angiogenesis and lens/retinogenesis defects are observed with lower penetrance (Ferretti et al., 2006). The surviving $25 \%$ Prep $1^{i / i}$ mice display a broad range of phenotypes, namely T-cell differentiation defects, impaired folliculogenesis, alteration of glucose and lipid metabolism (Longobardi et al., 2014). Moreover, cultured down-regulated mouse Prep $1^{1 / i}$ embryonic and human PREP1 fibroblasts accumulate double strand breaks and bypass oncogene-induced senescence, in the presence of an apparently functional DNA repair (lotti et al., 2011). This is due to anomalies in the timing of DNA replication and loss of DNA replication symmetry (Palmigiano et al., 2018). In fact Prep1 is a tumor suppressor: in mice the Prep $1^{i / f}$ mutants develop tumors at high frequency and in humans $75 \%$ of over 1,400 tumors show a major reduction of PREP1 expression (Longobardi et al., 2010). PREP1 also affects cell migration function, since its overexpression hijacks the TGF $\beta$ pathway inducing EMT (Epithelial-Mesenchimal Transition) in lung adenocarcinoma increasing the risk of metastasis (Risolino et al., 2014).

At the molecular level, Prep1 binds DNA as a dimer with Pbx1 (Longobardi et al., 2014). However, the dimer can also bind HoxB1 and possibly other anterior Hox proteins, since Prep1 interaction occurs with the $\mathrm{Pbx}$ moiety and is not alternative to that of $\mathrm{Pbx}$ with Hox. In this respect it has been shown that the ternary Prep1Pbx1-HoxB1 complexes can bind the HoxB1, HoxA2 enhancer regions and affect the expression of these Hox genes (Ferretti et al., 2000). Indeed, in D. rerio, Prep1.1 down-regulation results is a shut-off of the expression of several anterior HoxB genes in the hindbrain (De Florian et al., 2004).

Post-natal mammary gland develops through a process known as branching morphogenesis, whereby the epithelial bud extends into the fat pad and bifurcates to form an extensive ductal network (Affolter et al., 2003). Terminal End Buds (TEBs), located at the tip of the elongating ducts, sustain this process by providing mammary gland stem/progenitor cells (MaSC) (Paine and Lewis, 2017).

We now report that Prep 1 is expressed in differentiated ducts as well as in TEBs of the pre-pubertal mouse mammary gland and that its down-regulation, by multiple approaches, limits ducts branching. We also report that Prep1 function extends to the MaSC/progenitor compartment in which it sustains cell viability and branching differentiation, through a mechanisms that includes apoptosis and modulation of components of the partial EMT process.

\section{Results}

\section{Prep1 is expressed in mammary gland epithelial cells}

To bypass estral cycle influence on the mammary gland development, we have used in the majority of cases only pre-pubertal (4-5 weeks old) animals: older animals have been sometimes used (and indicated) to confirm the results obtained with younger ones.

A
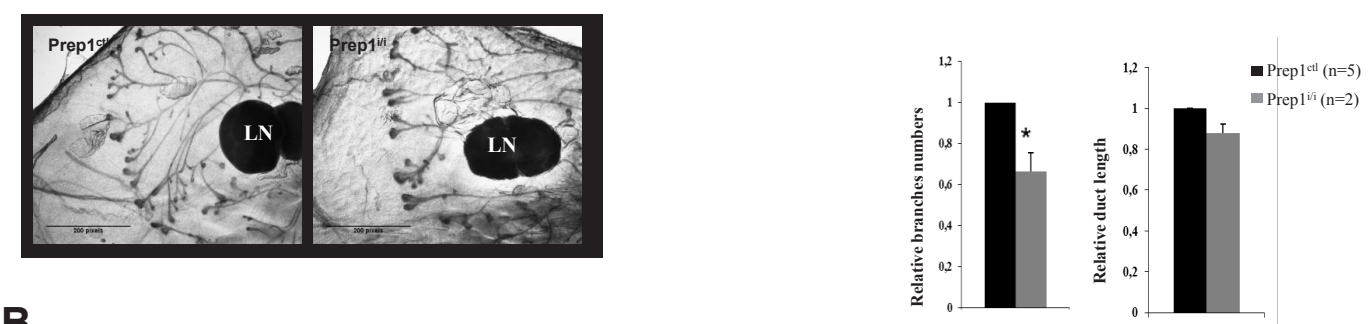

B

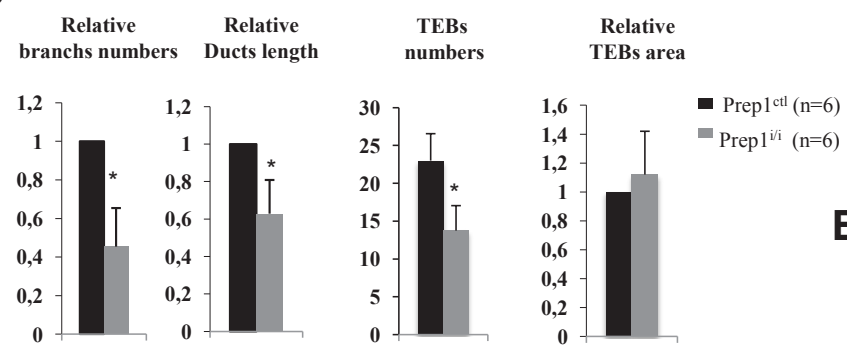

C
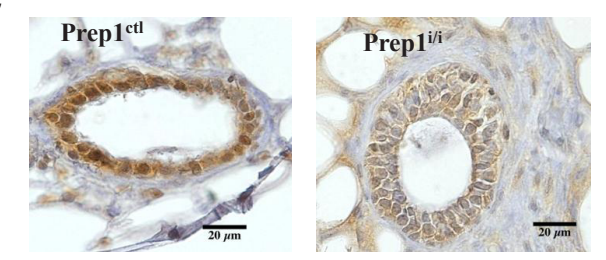

E

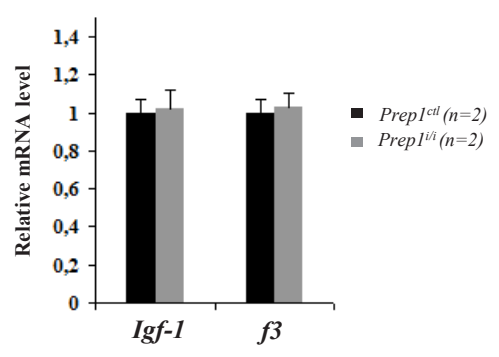

Fig. 1. Prep $1^{1 / i}$ mice show major defects in branching morphogenesis. (A) Representative images of Carmine Alum-stained whole-mount preparations of mammary glands from 4-5 weeks-old virgin Prep $1^{i i}$ female and age matched littermate control (Prep1 ${ }^{c t l}$ ) mice. LN: lymph nodes. (B) Quantification of the major structural features of the epithelial tree (branch numbers, ducts length, TEB numbers and area) observed in Prep $1^{\text {ii }}(n=6)$ as compared to Prep1 ${ }^{\text {ctl }}(n=6)$ glands. Detailed informations on quantifications are reported in Materials and Methods. Error bars indicate s.d. ( $\left.{ }^{*} P<0.01\right)$. (C) IHC with Prep1-specific antibody confirms the strong reduction of Prep1 signal in Prep1ii glands. Scale bars: 20

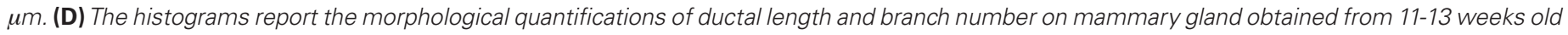

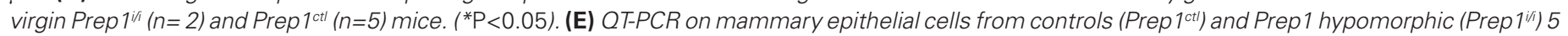

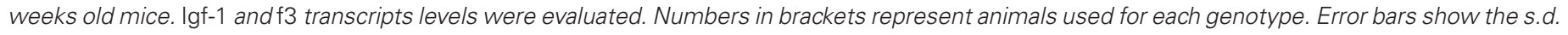


Immunofluorescence (IF) with a specific monoclonal antibody was used to localize Prep1 in the gland compartments of 4-5 weeks old virgin WT C57BL/6 mouse females. Specific staining for Prep1 was present in the epithelial and stromal cells (Fig. S1A, supplementary material). $\mathrm{HE}$ staining of the same section is also shown (Fig. S1B). Double IF with a $\alpha$-Smooth Muscle Actin (SMA) antibody, specific for the basal myoepithelial cells, revealed that Prep1 was mainly nuclear in SMA-positive myoepithelial and stromal cells but stained both nucleus and cytoplasm in luminal cells (Fig. S1 C,D in supplementary material). A similar pattern of expression was observed for Pbx1 (Fig. S1 E,F) the major transcriptional partner of Prep1 (Penkov et al., 2013). The presence of Prep1 in the cytoplasm may reflect either an excess over Pbx1 (since the latter transports it into the nucleus) (Berthelsen et al., 1999) or represent different stages of an unknown regulatory mechanism.

\section{Prep1 deficient females display defective mammary gland morphogenesis}

To assess the importance of Prep1 in pre-pubertal mammary gland development, we used the hypomorphic Prep $1^{i / i}$ mice. These mice were generated by insertion of a splice-site containing vector in the first intron of the Prep1 gene almost totally eliminating the WT Prep1 mRNA transcript, leaving only a residual $2-3 \%$ and about $7 \%$ of the protein (Ferretti et al., 2006). Whole-mounts of inguinal glands were prepared from 4-5 weeks-old control and Prep $1^{i / i}$ virgin females and stained over night in Carmine Alum solution. A representative image is shown in Fig. 1A. Quantitative analysis (Fig. 1B) shows a statistically significant reduction of branching (nearly 60\%) and of ducts length (nearly 40\%) in Prep $1^{\text {i/ }}$

\section{A}

Fig. 2. Prep1 is expressed in mouse mammospheres. (A) Top: SFE in re-plating experiments using mammary epithelial cells from 5 weeks-old C57BL/6 females cultured in sphere-promoting conditions. F1...F7 refer

to the serial replating. The inset shows an example of F2 mammosphere. Bottom: RT-PCR on total RNA from wild type F2 mammospheres. Prep 1, Cd24 and Cd49f transcripts were analysed (see Table S2 for specific primers). (B). Example of bright field and PKH26 epifluorescent F2 mammospheres. (C) Left: typical FACS profile of PKH26-labeled mammosphere cells with gated populations (see text); right: RT-PCR amplification of Prep1, Ki67, Cd24 and Cd49f mRNAs; gapdh amplification serves as a loading control. (D) Representative images of single cell suspensions obtained from F2 mammospheres labeled with PKH26 (red) and stained with Prep1 antibody (green). DAPI stains the nuclei. Notice that the PKH26 ${ }^{\text {pos }}$ cell does not stain for Prep 1.

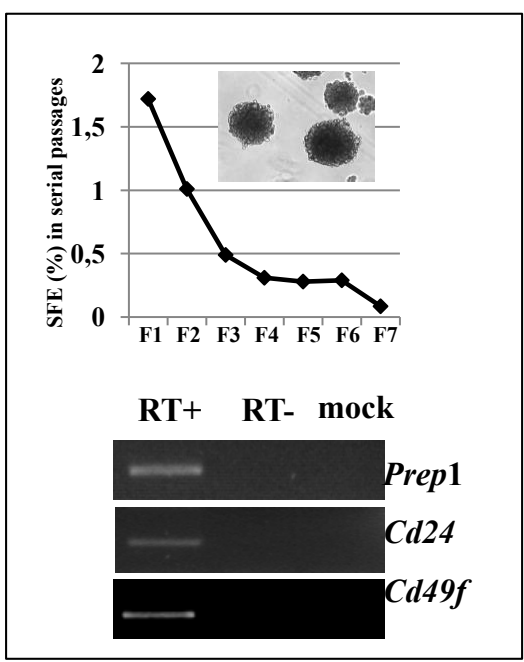

compared to control glands. In addition, we found a statistically significant reduction of the number of TEBs, but not of the TEBs area. Immunohistochemistry (IHC) with Prep1 specific antibody on paraffin-embedded mammary gland sections confirmed the reduction of Prep1 signal in Prep 1/ifemale glands (Fig. 1C).

To assess whether the morphological defects observed in Prep1 deficient mouse models persisted at later developmental stages, we extended our analysis to 11-13 weeks old virgin control and Prep $1^{i / i}$ females. Morphological quantifications, reported in the histograms in Fig. 1D, showed that at this developmental stage Prep $1^{i / i}$ duct length defect was no longer significant and hence mammary glands were as efficient as control glands to reach the limit of the fat pad; however, Prep $1^{i / i}$ glands still showed a significant impairment in branching morphogenesis.

At the onset of puberty, growth hormone $(\mathrm{GH})$ and estrogen (E2) sustain TEBs formation and branching morphogenesis (Paine and Lewis, 2017). To exclude that the branching phenotypes in Prep1 deficient mice might depend on aberrant hormonal responses, we tested Prep $1^{i / i}$ and Prep ${ }^{1 \text { cll }}$ mammary epithelial cells for Igf-1 and F3 mRNAs levels, downstream targets of $\mathrm{GH}$ and estrogen respectively (Kleinberg, 1998). The results, reported in Fig. 1E, revealed that $P$ rep $1^{i / i}$ epithelial cells expressed the same level of Igf- 1 and $F 3$ transcripts as control cells.

The branching phenotype was further confirmed by crossing a conditional Prep1 $1^{\text {floxed }}$ mouse (lotti et al., 2012), with the Ker5 Cre transgenic, in which the CRE activity (Ramirez et al., 2004), and hence Prep1 deletion, is restricted to the basal cells of stratified epithelia (not shown). Upon Prep1 deletion, ducts branching was significantly affected; however, the difference in TEB numbers did
B

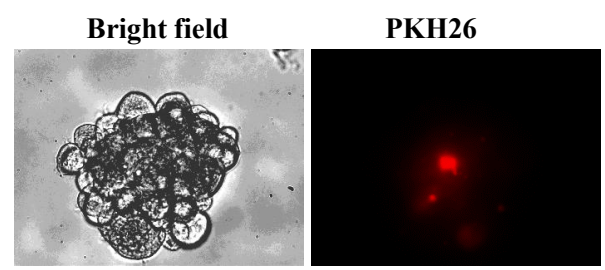

C
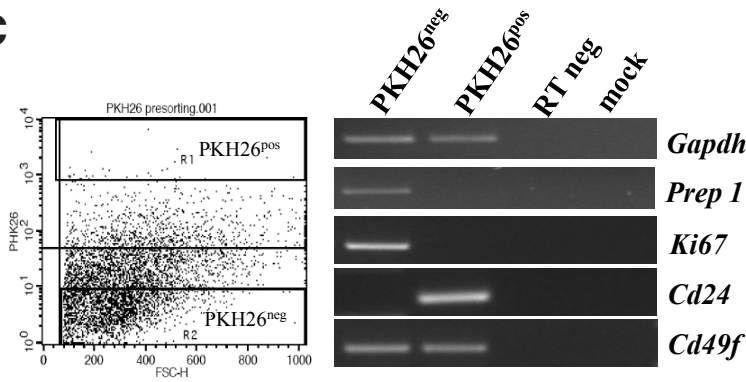

D
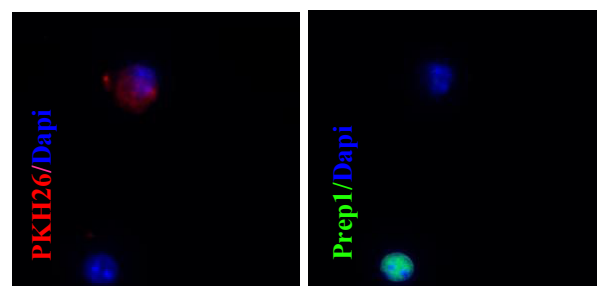
not reach statistical significance (Fig. S2 A,B in the supplementary material). Residual Prep1 mRNA in mammary epithelial cells (MEC), evaluated by RT-PCR amplifications, was not observed (supplementary Fig. S2C).

\section{Prep1 is expressed in mammary progenitor cells}

At puberty, with their pool of stem/progenitor cells, the TEBs represent the major structures driving ductal elongation and branching (Paine and Lewis, 2017; Scheele et al., 2017). We wondered whether down-regulation of Prep1 perturbed the mammary gland stem cell (MaSCs) niche within TEBs.

MaSCs can be cultured and propagated in-vitro, for at least 5-6 passages, under conditions promoting the formation of floating mammospheres. These are made up of a single, quiescent, mammary stem cell and many proliferating progenitors (Scheele et al., 2017). Using standard mammosphere-culturing conditions (see Methods) the spheres were propagated till the sixth (F6) serial passage (Fig. 2A). Evaluation of Prep1 expression in second passage (F2) mammospheres (insert, Fig. 2A) by RT-PCR shows a specific amplified band for Prep1; amplification of Cd49fand Cd24 mRNAs (Fig. 2A), two markers of mammary stem and progenitor cells (Stingl et al., 2006), confirms that the mammospheres contain

A

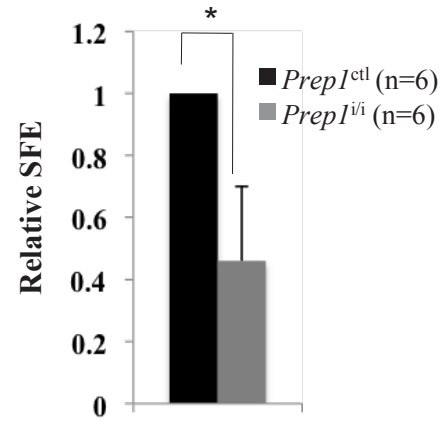

B

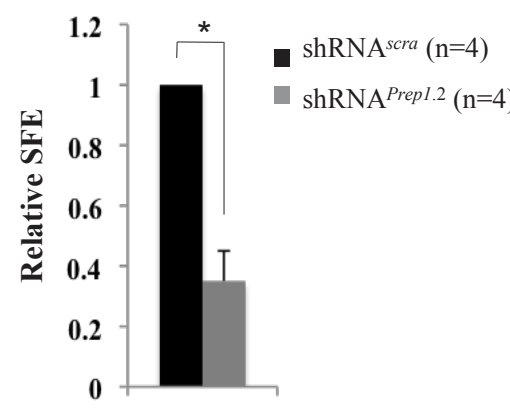

mammary stem and progenitor cells. Immunofluorescence on F2 mammospheres (Supplementary Fig. S3) confirms the presence of Prep1 in most mammosphere cells and its preferential nuclear localization; likewise, also Pbx1, partner of Prep1 in DNA binding, is expressed in the mammospheres. Prep1 distribution within the mammosphere was further investigated using $\mathrm{PKH} 26$ labeling, by which the quiescent MaSCs can be identified because they are able to retain the dye, unlike progenitor cells that divide and therefore dilute it (Pece et al., 2010). Mammary epithelial cells from 4-5 weeks old C57BL/6 mice were collected, stained with the lipophilic dye $\mathrm{PKH} 26$ and plated to form mammospheres. After two serial replating only few cells inside the F2 mammospheres retained the $\mathrm{PKH} 26$ epifluorescent signal (Fig. 2B), as expected. F2 mammospheres were collected and single cell suspensions used to differentially FACS-separate the most epifluorescent $0.2 \%-0.4 \%$ of the total cell population ( $\mathrm{PKH} \mathrm{H}^{\text {pos }}$ cells, gated at $10^{3}-10^{4}$ fluorescence units), from the $\mathrm{PKH}^{\text {neg }}$ proliferating, lineage-committed, progenitors (gated at $10^{0}-10^{1}$ fluorescence units) (Fig. $2 \mathrm{C}$, left). Total RNA was extracted and used in RT-PCR (Fig. 2C, right) to assess the presence of Prep1 mRNA in these two cell poulations. A Prep1 positive band was found in the $\mathrm{PKH} 26^{\text {neg }}$ but not in the $\mathrm{PKH} 26^{\text {pos }}$ population. Amplification of a band corresponding to CD24 and CD49f but not of Ki67 transcripts confirmed that the $\mathrm{PKH}^{\text {pos }}$ fraction was enriched in quiescent MaSC, as expected (Pece et al., 2010). The absence of Prep1 in the PKH26 ${ }^{\text {pos }}$ cells was further confirmed by double immunofluorescence: $\mathrm{PKH} 26^{\text {pos }}$ cells did not stain for Prep1, unlike PKH26 ${ }^{\text {neg }}$ cells (Fig. 2D). We conclude therefore that Prep1 is expressed in the $\mathrm{PKH} 26^{\text {neg }}$ progenitors population of the mammospheres.

We also evaluated the effect of Prep1 down-regulation on the mammary stem activity measuring the Sphere Forming Efficiency (SFE) (Shaw et al., 2012) upon replating in two different Prep1 down-regulated models: the hypomorphic Prep $1^{i / i}$ and the wt mam-
C

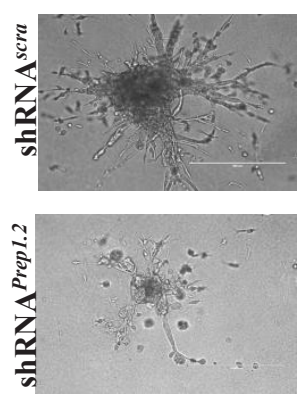

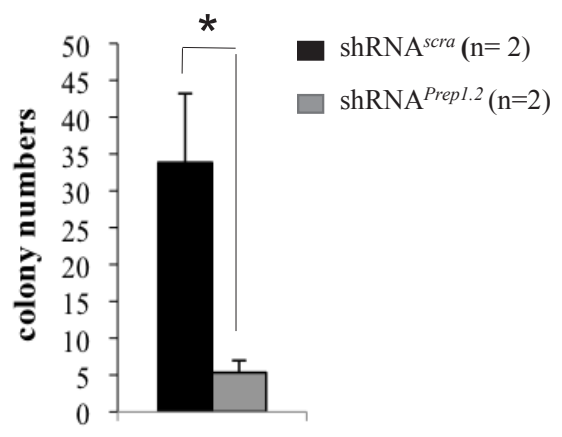

D

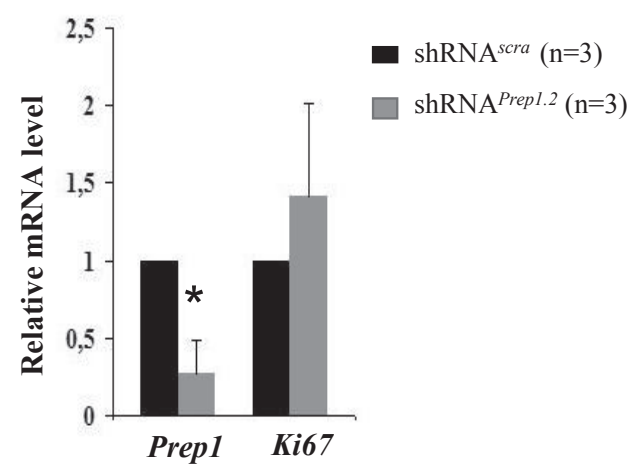

Fig. 3. Prep1-deficient MaSc/progenitors have a compromised Sphere Forming Efficiency (SFE). Purified MEC from Prep $1^{\text {if }}$ and Prep $1^{\text {ctl }}$ glands (A) and WT MEC transduced with shRNA scra $^{\text {or shRNA }}$ Prep1.2 lentiviruses (B) were seeded in low-adherence plates and grown as mammospheres. The SFE at passage 2 (F2) was evaluated. The number of animals (A) and the number of interference experiments (B) used for each experimental model is indicated in brackets, ( $\left.{ }^{*} \mathrm{P}<0.001\right)$. Bars show the s.d. (C) In-vitro branching potential of Prep1 deficient cells. MEC were infected with shRNA ${ }^{\text {Prep1.2 }}$ or shRNA scra viral supernatants and seeded in low-adherence plates and grown as mammospheres. After selection, the F2 cells were plated in Matrigel and cultured for 3 weeks for colony formation. Example of 3D colonies is shown on the left. Scale bar: 400 um. Quantification of colony number is reported in the histogram. Data refer to two independent experiments, each performed in triplicate. Bars indicate the s.d. (*P < 0.001). (D) Total RNA from F2 mammosphere cells interfered with shRNAPrep1.2 or shRNA scra viral supernatants was retrotrascribed and cDNA used to amplify Prep1 and Ki67 mRNAs. Data refer to three independent interference experiments, each in triplicate. Bars show the s.d.; * $p<0,01$. 
A

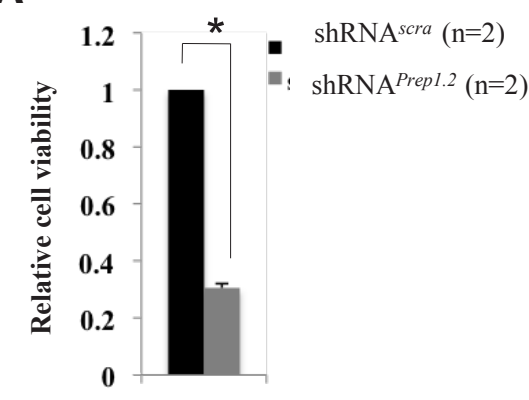

B

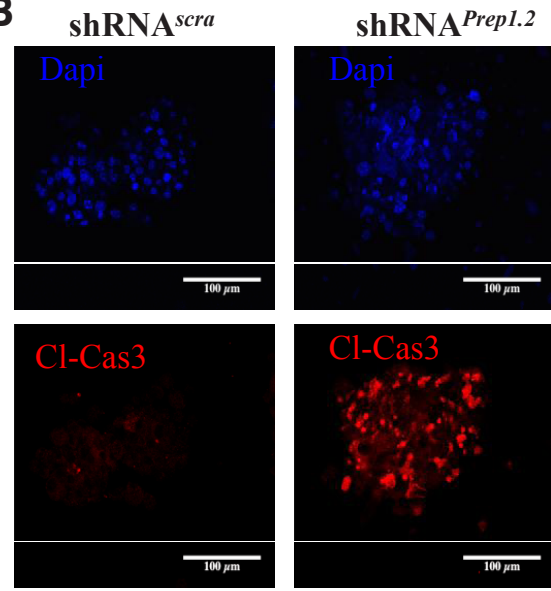

C

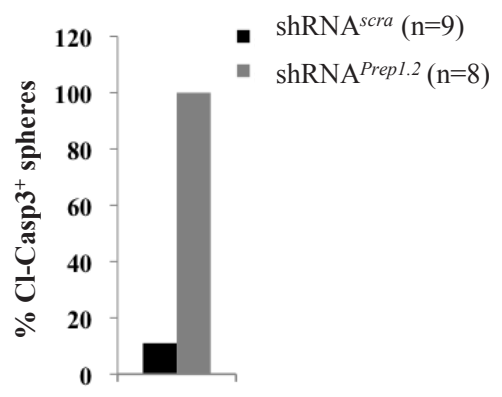

D

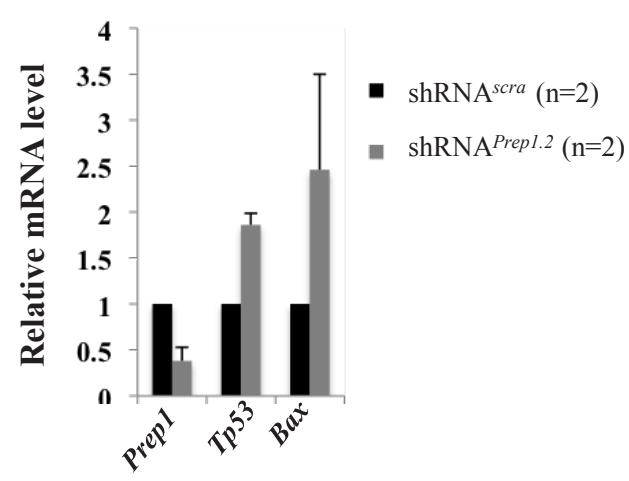

E

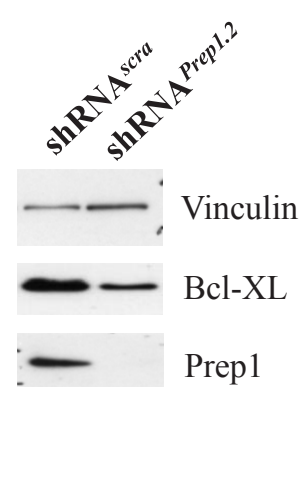

Fig. 4. Prep1-deficient mammosphere cells undergo apoptosis. Purified WT MECs transduced with shRNA ${ }^{\text {scra }}$ or shRNA Prep 1.2 lentiviruses were seeded in low-adherence plates, grown as mammospheres and used to asses cell viability. (A) Viability of F2 mammosphere derived cells by trypan blue exclusion; bars show the s.d. Data are the average of two independent experiments ( $\left.{ }^{*} \mathrm{P}<0.01\right)$. (B) Representative confocal immunofluorescence with Dapiand Cleaved Caspase-3 antibody on F2 mammospheres obtained from shRNA ${ }^{\mathrm{s}}$. cra or shRNA $A^{\text {Prep } 1.2}$ interfered cells (scale bars: $100 \mu \mathrm{m}$ ). (C) The histogram reports the percent of Cleaved Caspase-3 positive mammospheres. Numbers in brackets represent the numbers of mammospheres analyzed from two independent interference experiments. (D)

QT-PCR on total RNA from shRNA scra or shRNAPrep1.2 F2 mammospheres; Prep1, Tp53 and Bax mRNAs levels were evaluated. The data represent the average of two independent interference experiments. Error bars show the s.d. (E) Total lysate from shRNA scra or shRNA ${ }^{\text {Prep } 1.2}$ F2 mammospheres was electrophoresed on SDS-PAGE and immunoblotted with the indicated antibodies; vinculin served as a loading control.

mary gland epithelial cells in which Prep1 was down-regulated by transduction with a specific shRNA lentiviral vector. Supplementary Fig. S4A shows examples of the effects of Prep1 down-regulation in the two systems, whereas the graphs in Fig. $3 \mathrm{~A}, \mathrm{~B}$ show the quantification of the experiments. We observe a major decrease in SFE whenever Prep1 was down-regulated. The shRNA used in Fig. 3B and Fig. S4A in the supplementary material (shRNA Prep1.2) was the most efficient among the four tested (supplementary Fig. S4 B,C). A scrambled shRNA (shRNA ${ }^{\text {scra }}$ ) served as control.

We then used a 3D Matrigel assay (O'Brien et al., 2002) to test in-vitro the branching potential of shRNA ${ }^{\text {scra }}$ or shRNA ${ }^{\text {Prep 1.2-interfered }}$ mammosphere cells. In our experimental condition (see Materials and Methods), Prep1-interfered cells (shRNA ${ }^{\text {Prep1.2) }}$ show a much lower number of branches and shorter extensions (Fig. 3C) and form 6.5 fold less colonies in 3D Matrigel as compared to control cells (shRNA ${ }^{\text {scra) }}$ (histogram in Fig. 3C).

\section{Prep1 depleted MaSC/progenitor cells exhibit enhanced apoptosis}

Proliferation, apoptosis and cell migration of lineage-committed MaSC within the TEBs supportmammary branching morphogenesis (Scheele et al., 2017). Likely, Prep1 deficiency might interfere with these processes.
To assess the effect of Prep1 depletion on the proliferative behaviour of MaSC/progenitors, total RNA from F2 mammospheres, stably infected with shRNA ${ }^{\text {scra }}$ or shRNA ${ }^{\text {Prep } 1.2}$ lentiviruses was retrotranscribed and used for Ki67 mRNA amplification. The results, obtained from three independent interference experiments, reveal in Prep1 down-regulated cells a mild, and not significant, increase in Ki67 mRNA level (Fig. 3D).

We next evaluated the role of Prep1 on cell survival and found that Prep1 deficiency correlated with increased apoptosis. Indeed, cells from Prep1 down-regulated F2 mammospheres showed impaired viability ( $30 \%$ by Trypan blue exclusion; histogram in Fig. $4 \mathrm{~A}$ ) due to increased apoptosis as shown by the appearance of a strong cleaved Caspase-3 immunofluorescence signal (Fig. 4B). Quantification is reported in the histogram of Fig. 4C. The apoptotic behavior of Prep1-down-regulated F2 cells was further confirmed by the increased expression of the pro-apoptotic Tp53 and Bax mRNAs (Fig. 4D) and by the reduced level of the anti apoptotic Bcl-XL protein (Fig. 4E).

Activation of the MAPK pathway in the TEB region and acquisition of migratory behaviour by the resident cells are critical steps in mammary branching morphogenesis (Huebner et al., 2016). We tested to which extent Prep1 deficiency impacts on these processes by immunoblotting extracts from shRNA ${ }^{\text {Prep 1.2 and shRNA }}{ }^{\text {scra }}$ 
A

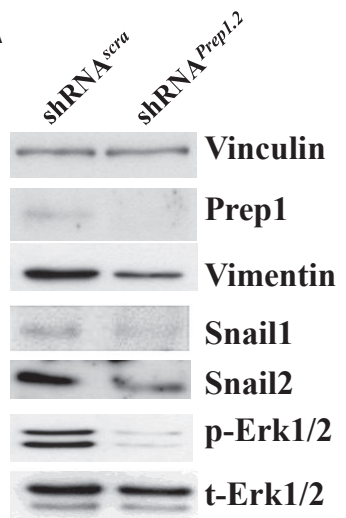

D

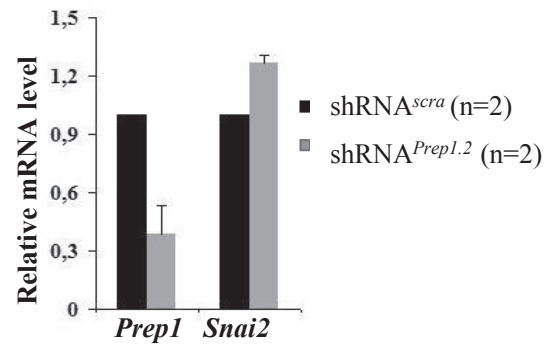

B

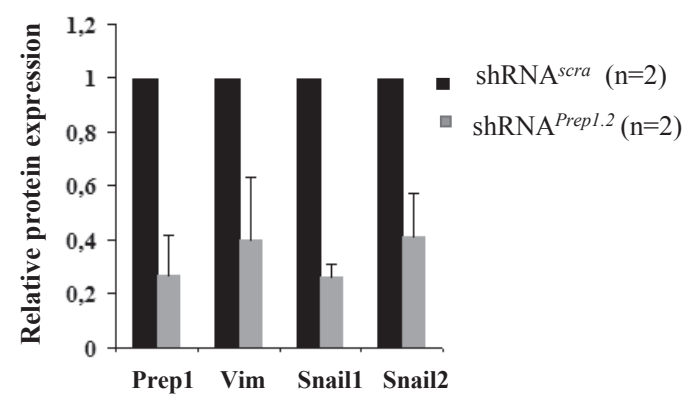

$\mathbf{E}$

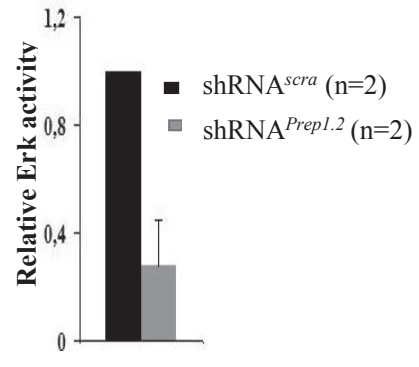

Fig. 5. Prep 1 is required to sustain physiological levels of Snail1, Snail2 and Vimentin in mouse mammary epithelial cells. (A) Total lysate from mouse mammosphere cells, infected with control (shRNA ${ }^{\text {scra }}$ ) or Prep1 specific shRNA (sh ${ }^{\text {Prep } 1.2)}$ lentiviral vectors, immunostained with antibodies against Prep1, Snail1, Snail2, Vimentin, totalErk (tErk) and phospho Erk (pErk) Vinculin served as a loading controls. The histograms in $(\mathbf{B}, \mathbf{C})$ show the densitometric quantification of Prep1, Snail1, Snai12 Vimentin and Er,k activity respectively; data refers to two independent interference experiments. Bars show the s.d. (D) Total RNA from F2 mammosphere cells interfered with shRNA $A^{\text {Prep1.2 }}$ or shRNA ${ }^{\text {scra }}$ viral

supernatants was extracted and cDNA used in QT-PCR to measure the levels of Prep1 and Snai2 mRNAs. Data refer to two independent experiments. Bars show the s.d. (E) Total RNA from MCF10A cells interfered with sh ${ }^{\text {PREP1 }}$ or sh ${ }^{\text {SCRA }}$ viral supernatants was extracted and cDNA used in QT-PCR to measure the levels of PREP1 and SNAI2 mRNAs. Data refer to two independent experiments. Bars show the s.d.

\section{A}

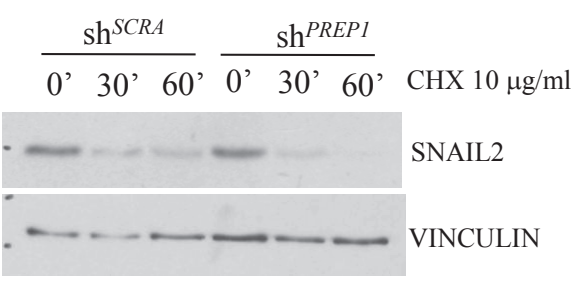

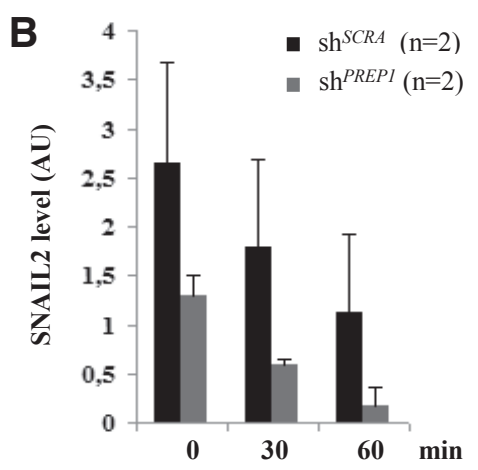

E

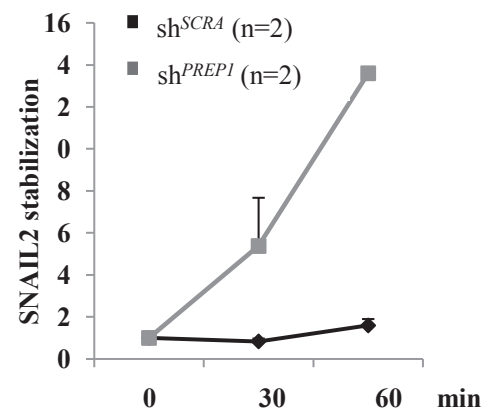

C

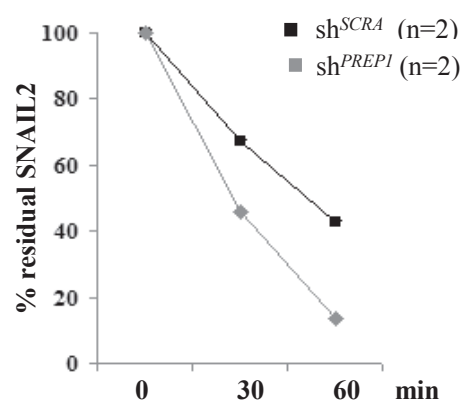

Fig. 6. PREP1 protects SNAIL2 from proteasome mediated degradation. (A) MCF10A control $\left(s h^{\text {s- }}\right.$

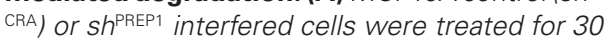
and $60 \mathrm{~min}$ with $\mathrm{CHX}(10 \mu \mathrm{g} / \mathrm{ml})$ and total lysate analysed by immunoblotting with the indicated antibodies. (B) The histogram shows the densitometric quantification of the immunoblots for SNAIL2 at different time points after $\mathrm{CHX}$ addition. (C) Percentage of residual SNAIL2 at various time points after the addition of CHX. The level at $t=$ $\mathrm{O}^{\prime}$ is considered as $100 \%$. (D) MCF10A control

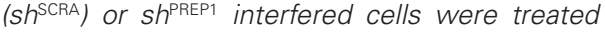
for 30 and 60 min with MG132 (20 $\mu \mathrm{M})$ and the total lysate analysed by immunoblotting with the indicated antibodies. (E) The panel shows SNAIL2 stabilization upon MG132 treatment, expressedas the ratio of the SNAIL2 signal measured at a given time after CHX addition with respect to that at $t=0$. Error bars show s.d. Data reported in panels $B$, $C$ and $E$ represent the average of two independent experiments. For both CHX and MG132 experiments, Vinculin served as loading control. 
-interfered F2 mammospheres using pERK, total ERK, Snail1, Snail2 and Vimentin antibodies. We found that Prep1 deficient cells showed attenuated Erk activity compared to control cell and a reduced Snail1, Snail2 and Vimentin level (Fig. 5 A-C). Similar results were observed in human MCF10A mammary gland cells (Soule et al., 1990), in which stable PREP1 down-regulation by a human Sh ${ }^{\text {PREP1 }}$ retrovirus, decreased ERK activity and SNAIL1, SNAIL2 and VIMENTIN signals (Fig. S5). IHC confirmed the reduced expression of Snail1 and Vimentin in mammary gland sections of 5 weeks old Prep1i/i mice (Fig. S6).

Overall these data indicate that MAPK signalling and mediators, required for branching morphogenesis, are severely compromised in the absence of Prep1.

\section{Prep1 protects Snail2 from proteasome mediated degradation}

Snail transcription factors are inducers of EMT and act as survival factors. In mammary branching morphogenesis Snail2 has been reported to protect cells from p53-dependent apoptosis (Lee et al., 2011). In our model of Prep1 down-regulation we found a concomitant p53-dependent apoptosis and reduction of Snail2 level.

As transcription factor, Prep1 might control Snail2 at the transcriptional level. However in both mammospheres and MCF10A models Snail 2 modulation depended on a post transcriptional mechanism since no variation in Snai2 mRNA level was observed in interfered compared to control cells (Fig. 5 D,E).

We previously reported that Prep1 is able to stabilize its $\mathrm{Pbx}$ cofactors by preventing proteasome-mediated degradation (Lon-

A
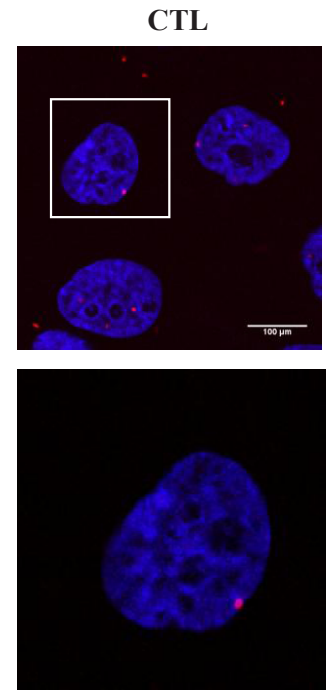

PREP1/SNAIL2
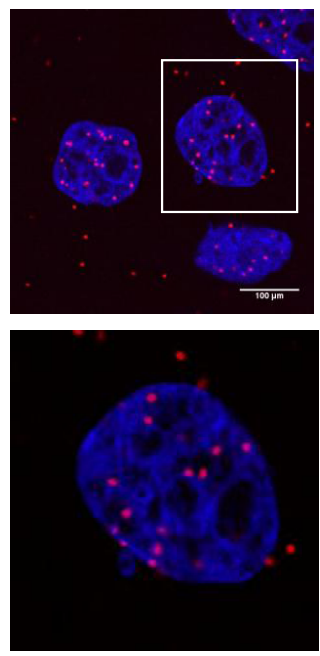

C

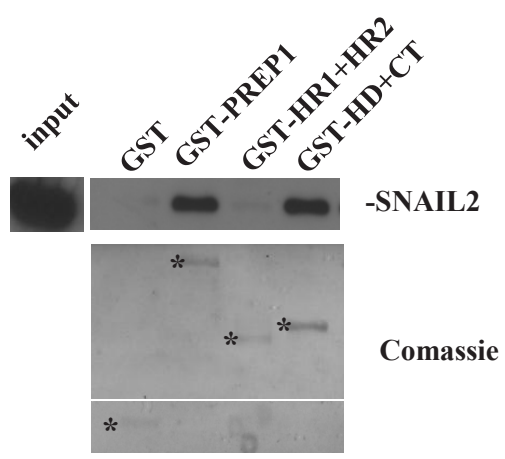

gobardi and Blasi, 2003). Therefore, Prep1 might have a similar protective role also on Snail2. To address this possibility MCF10A cells, stably interfered with shRNA ${ }^{P R E P 1}$ or control retrovirus particles, were treated for $30^{\prime}$ or 60 ' with the protein translation inhibitor cycloheximide $(\mathrm{CHX})$ and the total lysate analyzed by immunoblotting using the indicated antibodies (Fig. 6A). Treatment of cells with $\mathrm{CHX}$ resulted in a faster SNAIL2 degradation rate in PREP1 depleted cells as compared to the control cells, suggesting that in the mammary epithelial cells PREP1 stabilizes SNAIL2. Quantification of SNAIL2 level and residual SNAIL2 upon treatment at different time points are reported in Fig. $6 \mathrm{~B}$ and $\mathrm{C}$, respectively. The SNAIL2 degradation in PREP1 interfered cells was counteracted by the proteasome inhibitor MG132 (Fig. 6D). After 30' with MG132, SNAIL2 level in PREP1-depleted cells was comparable to the control cells and further increased at 60'. Quantification of SNAIL2 stabilization is reported in Fig. 6E. Overall, the data suggest that PREP1 is required to protect SNAIL2 from proteasomemediated degradation.

\section{PREP1 forms complexes with SNAIL2}

To accomplish its protective function, PREP1 might form a complex with SNAIL2. The in-situ proximity ligation assay (Soderberg et al., 2008) on MCF10Acell can evaluate the presence of PREP1/ SNAIL2-containing complexes. Indeed, in our experimental conditions, PREP1/SNAIL2 co-localization dots were present in the nuclei of the cells (red dots in Fig. 7A). We confirmed this interaction by pull-down experiment using MCF10A nuclear extract and recombi-

B

$$
\begin{aligned}
& \text { Prep1 }^{\text {wt }} \\
& \text { Prep1 }^{\text {HR1+HR2 }} \\
& \text { Prep1 }^{\mathrm{HD}+\mathrm{CT}}
\end{aligned}
$$

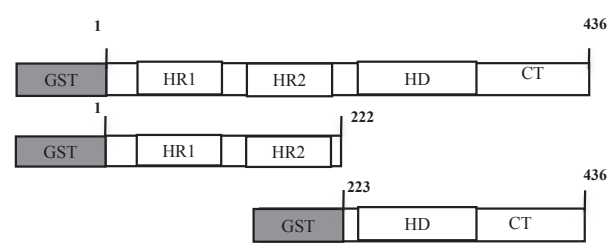

Fig. 7. PREP1 forms complexes with SNAIL2. (A) Confocal images of MCF10A cells tested in proximity ligation in-situ assay. Top panels: PREP1/ SNAIL2 complexes (red dots) were visualized by staining the cells with proximity probes directed against PREP1 and SNAIL2, followed by ligation and rolling circle amplification (see Methods). DAPI was used to stain the nuclei. Bottom panels: for a better evaluation of the PREP1/SNAIL2 colocalization dots, (red), higher magnification of selected areas from top panels are presented. In the control, PREP1 primary antibody was omitted in the staining procedure. Scale bars: $10 \mu \mathrm{m}$. (B) Schematic representation of different PREP1 constructs used in the pull down assay. (C) Bacterially purified GST or GST-PREP1 constructs (asterisks in the "Comassie" panel) were used as bait for pull down assay with MCF10A nuclear extract. The above panel shows the immunoblot with anti SNAIL2 antibody; input represents the MCF10A nuclear extract. SNAIL2 binds a fragment spanning residues 223-436 of PREP1. 
nant GST-PREP1 constructs missing individual domains of PREP1 (Fig. 7B). Indeed GST-PREP $1^{\text {wt }}$ and $\mathrm{GST}^{\mathrm{HD}+\mathrm{CT}}$ (containing only the homeodomain and the C-terminal fragment), but not GST ${ }^{\text {HR1 } 1+H R 2}$ (containing only the $\mathrm{N}$-terminal moiety of PREP1), pulled down SNAIL2 suggesting that the HD+CT region of PREP1 contains the domain involved in SNAIL2 complex formation (Fig. 7C).

\section{Discussion}

In this work we describe, for the first time, that Prep1 transcription factor and its major partner $\mathrm{Pbx} 1$ are present in the mouse mammary gland and contribute to the gland's branching morphogenesis. Prep1 and Pbx1 are expressed in differentiated luminal and myoepithelial ductal cells as well as in mammospheres (Fig S1 and Fig. S3). The cytoplasmic presence of Prep1 in luminal cells is not unique. Prep1 nuclear localization appears to be regulated, for example in the early stages of the zebrafish development (De Florian et al., 2004). Its significance and the mechanisms of regulation however are still obscure, although the cytoplasmic presence of Prep1 indicates an inactive state (Berthelsen et al., 1999). Prep1 deficiency correlates with branching defects of the differentiated cells and with the dysfunction of the stem/progenitor compartment, but not with impaired hormonal responses (Fig. 1E). Consistently, Prep1 is expressed in the mammospheres, and more precisely in the progenitors cells (Fig. 2), but genetic and shRNA-mediated ablation of Prep1 negatively impact on both stem and progenitor cells properties. Indeed Prep1 deficient MaSC/progenitor cells show a reduced SFE (Fig. $3 \mathrm{~A}, \mathrm{~B})$ and an impaired in-vitro branching potential (Fig. 3C). Moreover Prep1-ablated MaSC/progenitors do not properly activate MAPK signaling and are not able to express needed levels of Snail1, Snail2 and Vimentin. (Fig. 5 A-C) which are required to carry out $\mathrm{p}$-EMT.

Inhibition of apoptosis, activation of migration and $p$-EMT are required for branching morphogenesis (Lee et al., 2011). In the mammosphere model of Prep1 deficiency, all of these branching requirements are affected. Upon suboptimal expression of Prep1, mammary cells show up-regulation of inducers (Tp53, Bax) or executors (Cl-Caspase 3 ) of the apoptotic response and reduced expression of the anti apoptotic Bcl-XL protein (Fig. 4). This is in line with our previous works showing a Tp53 dependent apoptosis in Prep1\%- mouse epiblast cells and reduction of $\mathrm{Bcl}-\mathrm{XL}$ in Prep ${ }^{1 / i}$ mouse embryo fibroblasts (Fernandez-Diaz et al., 2010; Micali et al., 2009).

Snail proteins, and Vimentin are down-regulated in Prep1interfered cells as well as in mammary gland sections from Prep 1 hypomorphyc mice (Prep $\left.1^{i /}\right)$ suggesting that the $\mathrm{p}$-EMT program is also altered in Prep1 deficient mammary cells. Our data demonstrate that PREP1 forms complexes with SNAIL2 (Fig. 7) and that this interaction prevents the proteasome-mediated degradation of SNAIL2 (Fig. 6).

In addition to induce EMT Snails also act as survival factors. Overexpression of p53 and decrease of Snail2 in Prep1 deficient cells are in line with the repressive role of Snail2 over Tp53 reported by others (Kajita et al., 2004). Snail2 binds to Tp53promoter and its over-expression results in Tp53 mRNA inhibition (Kajita et al., 2004) while Snail2-interfered cells do not reduce p53 level in response to growth factors (Lee et al., 2011). We propose that in specific cell contexts and in response to specific stimuli, Prep1 forms complexes with Snail2 and regulates the transcription of
Tp53 and other target genes, mainly connected to self renewal, EMT, survival and DNA-damage. The presence of Prep1-Snail2containing complexes in the nuclei of the cells (Fig. 7A) supports this hypothesis. Snail genes are also potent inducers of EMT and cell migration. It is reasonable that Prep1-deficient mammary epithelial cells, in which we observe a consistent and concomitant reduction in Vimentin, Snail1 and Snail2 signals, could not migrate properly. Notably, we previously reported that overexpressed PREP1 induces EMT and confers prometastatic behaviour to A549 cells (Risolino et al., 2014). Our data on MAPK activation in Prep1-deficient cells further suggest migration impairment in the branching phenotype of Prep1 deficient gland.

Prep1- and Snai-deficient models share some common features. Snail1 and Snail2 are involved in development. Snai1 null embryos fail to produce mesoderm and do not gastrulate; Snai2 null mutants are viable although they express a broad range of defects. Snails are also connected to DNA-damage response and genomic instability. Deletion of Prep1 causes gastrulation arrest due to genomic instability (Fernandez-Diaz et al., 2010; Palmigiano et al., 2018), its down-regulation in Prep1 hypomorphic embryos likewise causes organogenesis defects (Ferretti et al., 2006) and alteration of stem/progenitor compartments. Importantly, down-regulation or deletion of Prep1 induce accumulation of DNA double strand breaks (lotti et al., 2011) by affecting the timing of replication of Lamin-associated DNA (Palmigiano et al., 2018) in agreement with the development of tumors (including mammary gland tumors) in Prep1 deficient mice and humans (Longobardi et al., 2010). Possibly, the developmental defects and the tumorprone phenotype of Prep1 deficient models might involve also Snail proteins. This possibility is worth being investigated.

Since Prep1 is a partner of Hox proteins via the intermediate binding of $\mathrm{Pbx} 1$, one wonders whether the present results are somehow intertwined with a role of Hox genes during mammary branching morphogenesis. Available information show that Hox genes are involved in the development of many branching organs and Hox deficiency causes branching defects (Patterson et al., 2001).

\section{Materials and Methods}

\section{Ethics statement}

All mice experiments were performed in accordance with Institutional Animal Care and Use Committee of IFOM and approved by the Italian Ministry of Health (project\#109/11). All animal handlings were in accordance with the guidelines established by EU (directive 2010/63/EU).

\section{Mice and genotyping}

4 to 5 weeks old C57BL/ 6 mice were purchased at Charles River Laboratories (Calco, LC- Italy) and housed according to institutional guidelines for 1 week before experiments were performed.

Prep $1^{i / i}$ mice have been previously described (Ferretti et al., 2006). Control animal (ctl) in all the experiments using the Prep $1^{\text {iif }}$ strain refers to wt or heterozygous animals. Prep1 floxed mice (Prep1 ${ }^{\text {tloxed; }}$ C57BL/6 background) were previously described (lotti et al., 2012). Prep $1^{\text {floxed }}$ mice (Prep 1/f) ) were crossed with a Prep1 1/- mice (Fernandez-Diaz et al., 2010) to generate Prep $1^{1 /-}$ mice. The mammary gland specific deletion was obtained by crossing Prep $1^{\text {t/ }}$ mice with transgenic SV129 Ker5Cre mice (Ramirez et al., 2004). Genotypes were determined by amplification of genomic DNA on tail biopsies using primers described in Fernandez-Diaz et al., (2010) for Prep1, whereas Ker5 primers (Table S1 in supplementary material) were used for Ker $5^{\mathrm{Cre}}$ transgene. Residual Prep1 expression in 
Mammary Epithelial Cells-enriched fraction was evaluated by RT-PCR using Prep1-full primers (Table S2 in supplementary material).

\section{Whole mounts and quantification of ductal morphogenesis}

The $4^{\text {th }}$ inguinal mammary glands were fixed overnight in Carnoy's II fixative and gradually rehydrated. Glands were stained with Carmine Alum over-night and cleared with Xylene. Whole-mount images were acquired using an Olimpus stereo microscope SZX16 and MetaMorph software (Molecular Devices, Sunnyvale, CA, USA). ImageJ software was used to quantify ductal morphogenesis. To quantify outgrowth, the distance of the most three longest ducts per gland was measured relative to a line tangential to the proximal lymph node in each animal. The branching points analysis was done by counting the number of bifurcations within a $200 \times 120$ pixel box; 3 boxes per one inguinal gland were analysed per mouse. To quantify TEB area, the average area of the 4 largest TEBs per whole-mount was obtained by outlining the TEB using the freehand selection tool. Statistical analysis was done by Student's t test

\section{Histology, immunofluorescence and IHC}

Tissue processing and HE staining were performed by the IFOM Pathology Unit according to standard procedures. Mammary glands immuno-stainings were performed according to standard procedure. Antigen retrieval was performed by incubating slides in $10 \mathrm{mM}$ sodium citrate $\mathrm{pH}$ 6.0. Slides were incubated in primary antibody over night and with secondary antibody for $45 \mathrm{~min}$, respectively. Sections were mounted with Eukitt (Invitrogen, Carlsbad, CA, USA). Images were collected with either a Leica TCS SP2 (confocal acquisition) or Olympus QColor 3TM digital camera and Hamamatsu Orca ER fluorescence camera and processed using ImageJ software.

\section{Dissociation of mammary tissue and mammosphere culturing}

Mammary glands from wt and Prep $1^{1 / i}$ mice were dissociated mechanically and enzymatically and single cell suspension used for mammospheres culturing as described (Tosoni et al., 2012). Briefly, freshly isolated mammary glands were collected, chopped with a scissor and the tissue fragments digested for 2-3 hr in DMEM (Lonza) supplemented with Collagenase (Sigma) and Hyaluronidase (Sigma). Cell suspension was serially filtered through a $100 \mu \mathrm{m}$ to $20 \mu \mathrm{m}$ cell strainer, resuspendend in PBS and residual blood cells removed by hypotonic lysis. Cells were resuspended in MEBM (Lonza) supplemented with $20 \mathrm{ng} / \mathrm{ml}$ EGF (Inalco), $20 \mathrm{ng} / \mathrm{ml} \mathrm{bFGF}$ (Peprotech), 0,5 $\mu \mathrm{g} / \mathrm{ml}$ Hydrocortisone (Sigma), $5 \mu \mathrm{g} / \mathrm{ml}$ insulin (Roche), $1 \mathrm{U}$ Heparin (Epsoclair), 2\% B27 Supplement (Gibco) and plated on polyEMA (Sigma) treated plates.

\section{PKH26 staining and FACS procedures}

Single cell suspensions from mammary glands from 4-5 weeks old C57BL/6 mice were labelled with PKH26 (Sigma) according to the manufacturer instruction. Labeled cells were plated in suspension and after 5-6 days, mammospheres were harvested, dissociated mechanically and re-plated for an additional mammosphere passage. Few (5-6) days later F1 mammospheres were collected, counted, dissociated mechanically and filtered through a $40 \mu \mathrm{m}$ cell strainer, and subjected to either FACS analysis with a FACS Vantage SE flow cytometer (Becton \& Dickinson) to yield $\mathrm{PKH} 26^{\text {pos }}$ and $\mathrm{PKH} 26^{\text {neg }}$ cells or used in immunofluorescence. Sorting conditions for $\mathrm{PKH} 26^{\text {pos }}$ and $\mathrm{PKH} 26^{\text {neg }}$ populations were described (Tosoni et al., 2012) with the exception of a gate of $10^{\circ}-10^{1}$ for $\mathrm{PKH}_{2} 6^{\text {neg }}$ fraction.

\section{Lentivirus infection of primary mammary epithelial cells}

Passage 1 mammospheres (F1) were collected, disgregated and single cell suspensions infected with PEG (System Biosciences)-concentrated lentivirus particles containing the following shRNAs (Open Byosystem): Scramble: ccggCAACAAGATGAAGAGCACCAACTCGAGTTGGTGCTCTTCATCTTGTTGttttg

shRNA ${ }^{\text {Prep 1.1: }}$ ccggCCCTACAACAGGGAAATGTAACTCGAGTTACATTTCCCTGTTGTAGGGttttg
shRNA ${ }^{\text {Prep1.2: }}$ ccggGCTTCAAGTCAACAACTGGTTCTCGAGAACCAGTTGTTGACTTGAAGCttttg shRNA ${ }^{\text {Prep 1.3: }}$ ccggGCTATCAAGATGGACAGCAAACTCGAGTTTGCTGTCCATCTTGATAGCtttttg

shRNA Prep1.4: ccggGCCATTTATAGGCATCCACTACTCGAGTAGTGGATGCCTATAAATGGCttttg

Infected cells were puromycin (PAA Laboratories)-selected and either plated for in-vitro SFE (Sphere Forming Efficiency) and branching morphogenesys or for protein and RNA extraction.

\section{D matrigel assay}

F1 derived mammary epithelial cells $\left(5 \times 10^{3}\right)$ were suspended in $1 \mathrm{ml}$ assay medium [MEBM: Ham's (1:1) supplemented with $2 \%$ FBS, $10 \mathrm{ng} / \mathrm{mL}$ EGF (Inalco), $5 \mu \mathrm{g} / \mathrm{mL}$ insulin (Roche), $1 \mu \mathrm{g} / \mathrm{mL}$ hydrocortisone (Sigma), $0.5 \mu \mathrm{g} / \mathrm{mL}$ cholera toxin (Sigma) and 2\% Matrigel (BD Bioscience)] and plated in 24 well plate. Cells were cultured for two weeks and then scored for colony numbers and morphology. A branching phenotype was defined as a sphere having at least two processes (branches) extending from its central body. Statistical analysis was done by Student's t test

\section{Cells}

MCF10A cells were cultured in DMEM/F12 (Invitrogen) supplemented with $100 \mathrm{ng} / \mathrm{mL}$ cholera toxin (Sigma-Aldrich), 0,5 $\mu \mathrm{g} / \mathrm{mL}$ hydrocortisone (Sigma), $10 \mu \mathrm{g} / \mathrm{mL}$ human insulin (Roche), $5 \%$ horse serum (Invitrogen) and $20 \mathrm{ng} / \mathrm{mL}$ EGF (Inalco). To obtain stable lines for PREP1 downregulation, MCF10A cells were infected with $S^{S C R A}$ or $S^{P R E P 1}$ retrovirus particles and selected with puromycin. The shRNAs used in this study were previously described (lotti et al., 2011). For MG132 and CHX experiments, cells were treated for 30 and $60 \mathrm{~min}$ and total extracts were processed for immunoblotting

\section{Western Blots, RT-PCR and RT-qPCR Analysis}

Nuclear and cytoplasmic extracts from mammary gland epithelial cells and mammospheres were obtained as previously described (Longobardi and Blasi, 2003). MCF10A and mammosphere total extract were obtained using Laemmli buffer. The antibodies used in this study are listed in Table $\mathrm{S} 1$ in supplementary material. Protein bands were visualized using the SuperSignal West Pico Substrate (Pierce, Rockford, IL) after incubation with HRP-conjugated anti-mouse, anti rabbit (Biorad) or anti-goat (Dako) secondary antibodies.

Isolation and purification of RNA was performed with the RNeasy Plus Mini Kit (QIAGEN GmbH, Hilden, Germany), followed by reverse transcription of total RNA with the Superscript ${ }^{\mathrm{TM}}$ III First Strand Synthesis System Kit (Invitrogen) according to manufacturer's instructions. The primer sequences used in this study are listed in Table S2 in the supplementary material. For QT-PCR, cDNAobtained with random hexamers (High Capacity cDNA Archive kit; Applied Biosystems) was amplified with the TaqMan Gene Expression assay (Applied Biosystems) and an ABI/Prism 7900 HT thermocycler. The probes to identify Igf1, F3, Snai2,, Tp53, Bax and Prep1 mRNAs were purchased by Applied Biosystem TaqMan gene expression assays (mouse; Snai2: Mm00441531_m1;; pKnox1: Mm00479320_m1; Tp53: Mm00441964_g1; Bax: Mm0043050_m1; lgf1:Mn00439560_m1; F3: Mn00438855_m1). Human: SNAI2 hs 00161904_m1; PKNOX1: hs 00231814_m1. GAPDH an 18S probes were used as reference genes.

\section{In-situ proximity-ligation assay}

In vivo complex formation in MCF10Acells was evaluated by Duo-Link in situ proximity ligation assay (Sigma) using SNAIL2 polyclonal and PREP1 monoclonal antibodies, according to manufacturer's protocol.

\section{GST-pull down and immunoprecipitation}

MCF10A nuclear extracts were obtained as previously described (Longobardi and Blasi, 2003), and used in pull down experiment. For GST-pull down experiments, $100 \mu \mathrm{g}$ of nuclear lysate were incubated for $1 \mathrm{hr}$ at $4{ }^{\circ} \mathrm{C}$ with GST and GST-PREP1 constructs (Diaz et al., 2007). Complexes were 
extensively washed, eluted with Laemmli buffer, separated on SDS-PAGE and immunostained with specific antibodies.

\section{Acknowledgements}

We wish to thank Dr. G. Bonizzi and Dr. L. Tosoni for technical advice and all members of the IFOM Imaging, Mouse Genetics and Histo-pathology facilities for their support. We are grateful to Dr. P.P Di Fiore. for the long discussions and scientific suggestions. FB was supported by grants from AIRC (ItalianAssociation for Cancer Research) n. 12829, the Italian Ministry of Health (2008-1228056) and the Cariplo Foundation, 2010.

\section{Author Contributions}

$E L, L S$, and FP performed experiments; EL designed experiments and analyzed the data with FB; SP provided the K5Cre mice and suggestions; $E L$ wrote the manuscript; EL and FB critically read the manuscript.

\section{References}

AFFOLTER M, BELLUSCI S, ITOH N, SHILO B, THIERY J P AND WERB, Z. (2003) Tube or not to tube: remodeling epithelial tissues by branching morphogenesis. Dev Cell 4: 11-18.

BERTHELSEN J, KILSTRUP-NIELSEN C, BLASI F, MAVILIO F AND ZAPPAVIGNA V. (1999) The subcellular localization of PBX1 and EXD proteins depends on nuclear import and export signals and is modulated by association with PREP1 and HTH. Genes Dev 13: 946-953.

DE FLORIAN G, TISO N, FERRETTI E, MEYER D, BLASI F, BORTOLUSSI M AND ARGENTON F. (2004) Prep1.1 has essential genetic functions in hindbrain development and cranial neural crest cell differentiation. Development 131: 613-627.

DİAZ VM, MORI S, LONGOBARDI E, MENENDEZ G, FERRAI C, KEOUGH RA, BACHI AAND BLASI F. (2007) p160 Myb-binding protein interact with Prep1 and inhibits its transcriptional activity. Mol Cell Biol 27: 7981-7990.

FERNANDEZ-DIAZ LC, LAURENT A, GIRASOLI S, TURCO M, LONGOBARDI E, IOTTI G, JENKINS NA., FIORENZA MT, COPELAND NG AND BLASI F. (2010) The absence of Prep1 causes p53-dependent apoptosis of pluripotent epiblast cells. Development 137: 3393-3403.

FERRETTI E, MARSHALL H, POPPER H, MACONOCHIE M, KRUMLAUF R AND BLASI F. (2000) Segmental expression of Hoxb2in r4 requires two separate sites that integrate cooperative interactions between Prep1, Pbx and Hox protein. Development 127: 155-166.

FERRETTIE, VILLAESCUSAJC, DIROSAP, FERNANDEZ-DIAZLC, LONGOBARDI E, MAZZIERI R, MICCIO A, MICALI N, SELLERI L, FERRARI G. et al., (2006) Hypomorphic mutation of the TALE gene Prep1 ( $p$ Knox1) causes a major reduction of $\mathrm{Pbx}$ and Meis proteins and a pleiotropic embryonic phenotype. Mol Cell Biol 26: 5650-5662.

HUEBNER, R.J., NEUMANN, N.M. and EWALD, A.J. (2016) Mammary epithelial tubes elongate through mapk-dependent coordination of cell migration. Development 143: 983-993.

IOTTI G, LONGOBARDI E, MASELLAS, DARDAEI L, DE SANTIS F, MICALI N AND BLASI F. (2011) Homeodomain trascription factor and tumor suppressor Prep1 is required to maintain genomic stability. Proc Natl Acad Sci 108: E314-322.

IOTTI G, MEJETTA S, MODICA L, PENKOV D, PONZONI M, BLASI F. (2012) Reduction of Prep1 levels affect differentiation of normal and malignant $B$ cells and accelerates Myc driven lymphomagenesis. PLOS ONE 7: E48353.

KAJITA M, MCCLINIC KN AND WADE P. (2004) Aberrant Expression of the transcription factor snail and slug alters the response to genotoxic stress. Mol. Cell. Biol. 24: 7559-7566.

KLEINBERG DL. 1998. Role of IGF-I in normal mammary development. Breast Canc. Res. Treat. 47: 201-208.

LEE KA, GJOREVSKI N, BOGHAERT E, RADISKY DC AND NELSON CM. (2011) Snai1, Snail2, and $E 47$ promote mammary epithelial branching morphogenesis. EMBO J 30: 2662-2674.

LONGOBARDI E AND BLASI F. (2003) Overexpression of PREP-1 in F9 teratocarcinoma cells leads to a functionally relevant increase of PBX-2 by preventing its degradation. J Biol Chem 278: 39235-39241.

LONGOBARDI E, IOTTI G, DI ROSA P, MEIETTA S, NUCIFORO P, PONZONI M, DOGLIONI C, CANIATTI M, BIANCHI F, DI FIORE PP et al., (2010) The homeodomain transcription factor Prep1 gene (pKnox1) is a haploinsufficient tumor suppressor in man and mice. Mol Oncol 4: 226-234.

LONGOBARDIE, PENKOV D, MATEOS D, DE FLORIAN G, TORRES M AND BLASI F. (2014) Biochemistry of the TALE transcription factors PREP, MEIS and PBX in vertebrates. Dev Dyn. 243: 59-75.

MICALI N, FERRAI C, FERNANDEZ-DIAZ LC, BLASI F AND CRIPPA PM. (2009) Prep1 directly regulates the intrinsic apoptotic pathway by controlling $B c \mid-X_{L}$ levels. Mol Cell Biol 29: 1143-1151.

O'BRIEN LE, ZEGERS MM AND MOSTOV, KE. (2002) Opinion: Building epithelial architecture: insights from three-dimensional culture models. Nat Rev Mol Cell Biol 3: 531-537.

PAINE IS AND LEWIS MT. (2017) The terminal End Bud: the little Engine that Could. J Mammary Gland Biol Neoplasia 22: 93-108.

PALMIGIANO A, SANTANIELLO F, CERUTTI A, PENKOV D, PURUSHOTHAMAN D, MAKHIJA E, LUZI L, DI FAGAGNA FD, PELICCI PG, SHIVASHANKAR V, DELLINO GI, BLASI F. 2018. Sci. Rep 16: 3198.

PATTERSON LT, PEMBAUR M, POTTER SS, 2001. Hoxa11 and Hoxd11 regulate branching morphogenesis of the ureteric bud in the developing kidney. Development 128: 2153-2161.

PECE S, TOSONI D, CONFALONIERI S, MAZZAROL G, VECCHI M, RONZONI S, BERNARD L, VIALE G, PELICCI PG, DI FIORE PP. (2010) Biological and molecular heterogeneity of breast cancer correlates with their cancer stem cell content. Cell 140: 62-73.

PENKOV D, MATEOS SM, FERNANDEZ-DIAZ LC, ROSELLO CA, TORROJA C SANCHEZ-CABO F, WARNATZ HJ, SULTAN M, YASPO ML, GABRIELI A et al., (2013) Analysis of the DNA-Binding Profile and Function of TALE Homeoproteins Reveals Their Specialization and Specific Interactions with Hox Genes/Proteins. Cell Reports 25: 1321-1333.

RAMIREZ A, PAGE A, GANDARILLAS A, ZANET J, PIBRE S, VIDAL M, TUSELL L, GENESCA A, WHITAKER DA, MELTON DW et al., (2004) A keratin K5Cre transgenic line appropriate for tissue-specific or generalized cre-mediated recombination. Genesis 39: 52-57.

RISOLINO M, MANDIAN, IAVARONE F, DARDAEI L, LONGOBARDIE, FERNANDEZ S, TALOTTA F, BIANCHI F, PISATI F, SPAGGIARI L et al., (2014) Transcription factor PREP1 induces EMT and metastasis by controlling the TGF-b-SMAD3 pathway in non-small cell lung adenocarcinoma. Proc Nat Acad. Sci. USA 111: e3775-e3784.

SCHEELE CLGJ, HANNEZO E, MURARO MJ, ZOMER A, LANGEDIIJK NSM, VAN OUDENAARDENA, SIMONSBD \& VAN RHEENEN J. (2017) Identity and dynamics of the mammary stem cells during branching morphogenesis. Nature 542:313-317.

SELLERI L, DEPEW MJ, JACOBS Y, CHANDA SK, TSANG KY, CHEAH KS, RUBENSTEIN JL, O'GORMAN S AND CLEARY ML. (2001) Requirement for Pbx1 in skeletal patterning and programming chondrocyte proliferation and differentiation. Development 128: 3543-3557.

SHAW FL, HARRISON H, SPENCE K, ABLETT PM, SIMOES BM, FARNIE G, CLARKE RB. (2012) A detailed Mammosphere Assay Protocol for the quantification of Breast Stem Cell Activity. J Mammary Gland Biol. Neoplasia.17: 111-7.

SODERBERG O, LEUCHOWIUS KJ, GULLBERG M, JARVIUS M, WEIBRECHT I, LARSSON LG AND LANDERGEN U. (2008) Characterizing proteins and their interactions in cells and tissues using the in situ proximity ligation assay. Methods 45: 227-232.

SOULE HD, MALONEY TM, WOLMAN SR, PETERSON WD, BRENZ R, MCGRATH CM, RUSSO J, PAULEY RG, JONES RF AND BROOKS SC. (1990) Isolation and characterization of a spontaneously immortalized human breast epithelial cell line, MCF10A. Cancer Res 50: 6075-6086.

STINGL J, EIREW P, RICKESTON I, SHACKLETON M, VAILLANT F, CHOI D, LI H AND EAVES CJ. (2006) Purification and unique properties of mammary epithelial stem cells. Nature 439: 993-997.

TOSONI D, DI FIORE PP AND PECE S. (2012) Functional purification of human and mouse mammary stem cell. Methods Mol Biol 916: 59-79. 


\section{Further Related Reading, published previously in the Int. J. Dev. Biol.}

Prolactin stimulation affects the stem cell-dependent mammary repopulating ability of embryonic mammary anlagen Jiazhe Song, Fangrong Ding, Song Li, Siying Peng, Yixiang Zhu and Kai Xue

Int. J. Dev. Biol. (2018) 62: 623-629

https://doi.org/10.1387/ijdb.180109kx

\section{An immunohistochemical analysis of Rab27B distribution in fetal and adult tissue}

An Hendrix, Kathleen Lambein, Wendy Westbroek, Miguel C. Seabra, Veronique Cocquyt, Patrick Pauwels, Marc Bracke, Christian Gespach and Olivier De Wever

Int. J. Dev. Biol. (2012) 56: 363-368

https://doi.org/10.1387/ijdb.120008ah

\section{Exosome signaling in mammary gland development and cancer}

An Hendrix and Alistair N. Hume

Int. J. Dev. Biol. (2011) 55: 879-887

https://doi.org/10.1387/ijdb.113391ah

Recent insights into the effect of natural and environmental estrogens on mammary development and carcinogenesis Vassiliki Pelekanou and Guy Leclercq Int. J. Dev. Biol. (2011) 55: 869-878

https://doi.org/10.1387/ijdb.113369vp

Non-steroidal anti-inflammatory drugs target the pro-tumorigenic extracellular matrix of the postpartum mammary gland

Jenean O’Brien, Kirk Hansen, Dalit Barkan, Jeffrey Green and Pepper Schedin Int. J. Dev. Biol. (2011) 55: 745-755

https://doi.org/10.1387/ijdb.113379jo

Ecosystems of invasion and metastasis in mammary morphogenesis and cancer Marc Mareel and Susana Constantino Int. J. Dev. Biol. (2011) 55: 671-684

https://doi.org/10.1387/ijdb.113386mm

Developmental and cancer research on the mammary gland nowadays Marc Bracke and Olivier De Wever Int. J. Dev. Biol. (2011) 55: 667-669 https://doi.org/10.1387/ijdb.113421mb

5 yr ISI Impact Factor $(2016)=2.421$
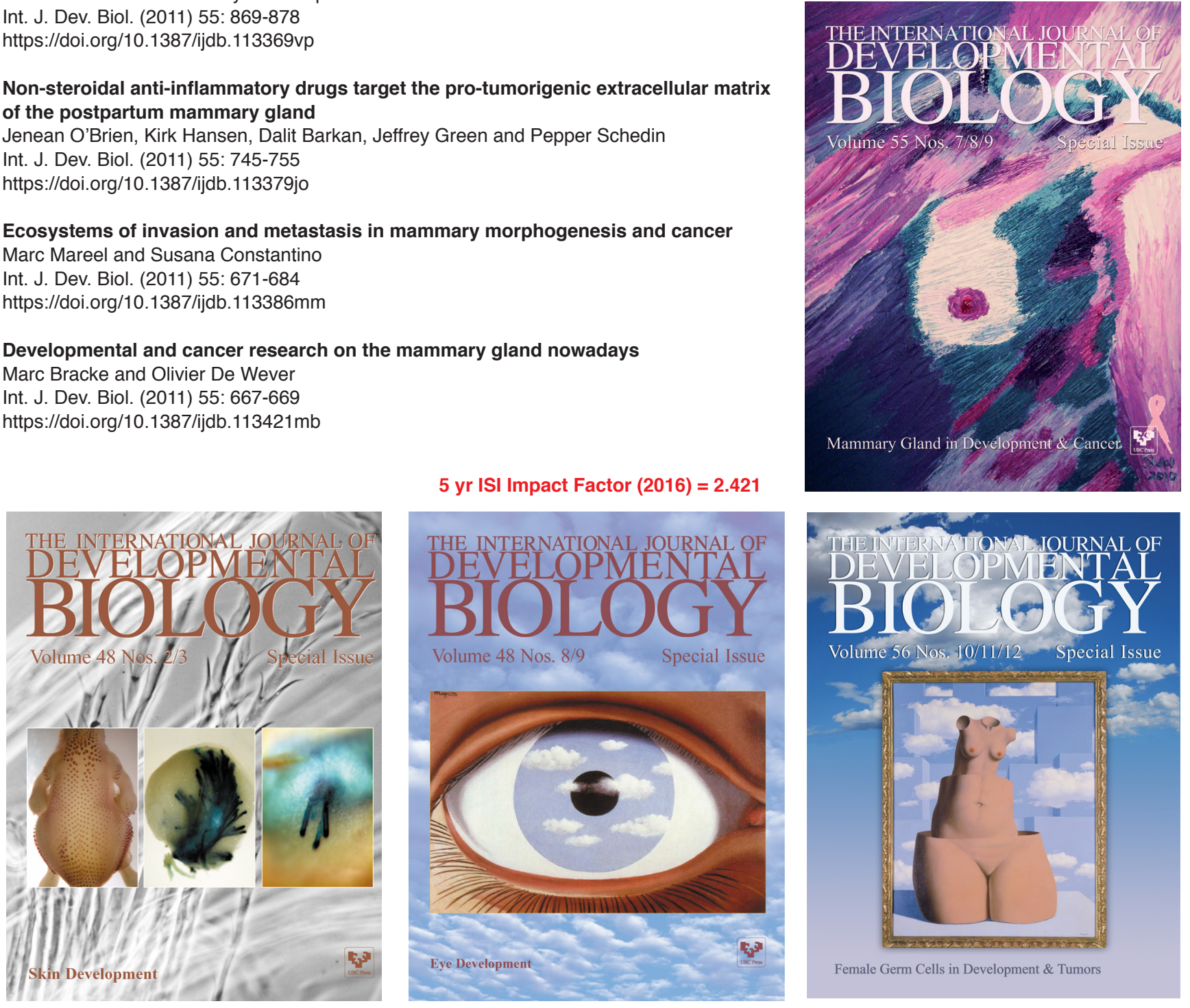